\title{
General practitioner outpatient referrals: do good doctors refer more patients to hospital?
}

\author{
G A Reynolds, J G Chitnis, M O Roland
}

\begin{abstract}
Objective-To investigate the relation between general practitioners' referral rates to individual specialties and the individual areas of expertise of the referring doctors.

Design-Data collected on referral patterns in one group practice over nine months.

Setting-General practice in suburban Birmingham consisting of five partners and a trainee.

Results-In 395 referrals there were large differences in referral patterns among partners for otorhinolaryngology, ophthalmology, general surgery, and dermatology. The doctors with particular expertise in otorhinolaryngology and ophthalmology had high referral rates to those specialties, and these differences persisted after allowing for case mix.

Conclusion-A high referral rate does not necessarily imply a high level of inappropriate referral.
\end{abstract}

\section{Introduction}

The performance of general practitioners in relation to outpatient referral has become a topic of considerable interest, particularly in view of current moves to initiate clinical audit in general practice. Much attention has been focused on the wide range of referral rates among general practitioners and on whether such variation reflects widely varying standards of clinical practice.

It has previously been suggested that practitioners with particular areas of interest may have higher referral rates in those specialties in which they have skills. ${ }^{2}$ A possible explanation for this may be differences in case mix, in that practitioners with particular knowledge may be referred cases by their partners, or patients may learn about a doctor's special interest and make a conscious decision about whom to consult for a particular problem. We studied referral behaviour of practitioners in a group practice, with particular reference to specialties in which individual practitioners had expertise.

\section{Poplars Surgery, Castle Bromwich, Birmingham B36 0HH G A Reynolds, MRCGP, general practitioner traine J G Chitnis, MRCGP, general practitioner}

Cambridge University School of Clinical Medicine, Addenbrooke's Hospital, Cambridge CB2 2QQ

$M$ O Roland, DM, director of studies in general practice

Correspondence to: Dr G A Reynolds, Market Cross Surgery, Mildenhall, Suffolk IP28 7EG.

\section{Method}

The study was conducted over nine months, from 1 July 1988 to 31 March 1989 . The practice is a group practice with four full time partners (three male, one female), one part time partner (female), and a trainee. Special interests among the partners include otorhinolaryngology (one hospital practitioner), ophthalmology (one partner with a diploma in ophthalmology and over five years' experience at registrar level), diabetes (one partner as clinical assistant), and gynaecology and family planning (two female partners, one with MRCOG, one as clinical assistant). The practice population consists of 11500 patients spanning a wide range of social class. The practice is non-dispensing, covers a suburban area in East Birmingham, and is based in two practice owned premises a mile apart, each operating an appointment system.

Between 1 July 1988 and 31 March 1989 a record was made of the number of consultations performed in surgery by each practitioner. In addition, outpatient referrals by each doctor were identified from a file in which was kept an extra copy of every typed referral letter (both NHS and private) between these dates. Emergency referrals and those patients urgently referred to hospital with handwritten letters were not included in the study. In view of the practice's involvement in intrapartum care and the consequent complex referral procedures, maternity cases were also excluded from the study. From this information a referral rate (defined as the number of referrals per 100 consultations) could be calculated for each practitioner.

For each individual referral, information was recorded from the referral letter on the specialty; nature of referral (NHS or private); the patient (age/sex); and the identity of the referring doctor. So that the study could be completed while the first author (the trainee) was with the practice, individual cases were entered into the study only on receipt of a hospital letter relating to the referral. Analysis is therefore of those referrals of patients that were seen during the nine month period of the study.

When the initial results were analysed, large differences in referral rates between the doctors were found for some specialties. The doctors with particular expertise in otorhinolaryngology and ophthalmology were found to have high rates of referral to those specialties. As this could have been due to these doctors seeing more cases in their specialties it was decided to record prospectively, over a six week period, the proportion of each practitioner's consultations related to otorhinolaryngology and ophthalmology so that any significant differences in case mix of patients seen by the five doctors could be determined. A six week period was chosen as this would allow sufficient data to be collected for the least common specialty (ophthalmology) for the coefficient of variation of the mean number of consultations per practitioner over that period to be less than $20 \%$.

Several months after these data had been collected a standard questionnaire was used to assess the relative confidence of each practitioner in regard to the 10 most common specialties to which referral took place.

All information was coded on to standard sheets for entry into the Cambridge University mainframe computer. To determine which specialties had referral patterns that were particularly variable, a method based on the proportional hazards model was used to separate the total variation in referral rates by doctors into random and systematic components. ${ }^{34}$ The ratio of the systematic component of variance within a specialty to the random component can be compared with the $F$ distribution using $n-1$ degrees of freedom, $\mathrm{n}$ being the number of doctors. This indicates whether the systematic variation between doctors' referral rates within a specialty is greater than would be expected by chance.

\section{Results}

The total number of outpatient referrals over the nine months of the study was 612 , with a total of 21784 surgery based consultations - an overall referral rate of $2 \cdot 8$ referrals per 100 consultations (ranging from $1 \cdot 6$ 


\begin{tabular}{|c|c|c|c|c|c|c|c|c|c|c|}
\hline \multirow[b]{2}{*}{ Specialty } & \multicolumn{6}{|c|}{ No $(\%)$ by referrals by doctors } & \multicolumn{4}{|c|}{ Variation } \\
\hline & A & B & $\mathrm{C}$ & $\mathrm{D}$ & $\mathrm{E}$ & Total & $\begin{array}{l}\text { Systematic } \\
\text { component }\end{array}$ & $\begin{array}{c}\text { Random } \\
\text { component }\end{array}$ & $\begin{array}{c}\text { Systematic/ } \\
\text { random } \\
\text { component }\end{array}$ & $\begin{array}{c}\text { p Value } \\
\left(F_{4,4}\right)\end{array}$ \\
\hline Medicine & $6(15)$ & $6(15)$ & $4(10)$ & $17(43)$ & $7(18)$ & 40 & 1.51 & $0 \cdot 12$ & $12 \cdot 2$ & $<0.05$ \\
\hline Surgery & $24(25)$ & $8(8)$ & $15(16)$ & $39(41)$ & $10(10)$ & 96 & $1 \cdot 50$ & 0.05 & 28.9 & $<0 \cdot 01$ \\
\hline Orthopaedics and rheumatology & $10(29)$ & $4(12)$ & $10(29)$ & $8(24)$ & $2(6)$ & 34 & 0.59 & $0 \cdot 14$ & $4 \cdot 1$ & NS \\
\hline Otorhinolaryngology & $24(47)$ & $3(6)$ & $9(18)$ & $15(29)$ & & 51 & $2 \cdot 62$ & 0.09 & $27 \cdot 8$ & $<0.01$ \\
\hline Ophthalmology & $3(12)$ & & $21(81)$ & $2(8)$ & & 26 & $8 \cdot 82$ & $0 \cdot 18$ & $49 \cdot 4$ & $<0.01$ \\
\hline Dermatology & $4(13)$ & & $7(23)$ & $17(55)$ & $3(10)$ & 31 & $4 \cdot 07$ & $0 \cdot 16$ & $25 \cdot 2$ & $<0.01$ \\
\hline Gynaecology & $9(15)$ & $11(18)$ & $12(20)$ & $20(33)$ & $9(15)$ & 61 & $0 \cdot 41$ & $0 \cdot 07$ & $5 \cdot 5$ & NS \\
\hline Urology & $2(18)$ & & $1(9)$ & $7(64)$ & $1(9)$ & 11 & $5 \cdot 67$ & $0 \cdot 45$ & $12 \cdot 5$ & $<0.05$ \\
\hline Paediatrics & & $1(14)$ & $3(43)$ & $3(43)$ & & 7 & $3 \cdot 18$ & $0 \cdot 71$ & $4 \cdot 5$ & NS \\
\hline Psychiatry & $1(11)$ & $1(11)$ & $1(11)$ & $4(44)$ & $2(22)$ & 9 & 1.53 & 0.55 & $2 \cdot 8$ & NS \\
\hline Other & $4(14)$ & $7(24)$ & $14(48)$ & $4(14)$ & & 29 & & & & \\
\hline Total & $87(22)$ & $41(10)$ & $97(25)$ & $136(34)$ & $34(9)$ & 395 & $0 \cdot 27$ & 0.01 & & $<0.01$ \\
\hline
\end{tabular}

NS $=$ not significant.

TABLE II - Percentage (95\% confidence interval) of referrals and consultations in two specialties by general practitioners in one group practice

\begin{tabular}{|c|c|c|c|c|c|c|c|c|}
\hline \multirow[b]{3}{*}{ Doctor } & \multicolumn{4}{|c|}{ Otorhinolaryngology } & \multicolumn{4}{|c|}{ Ophthalmology } \\
\hline & \multicolumn{2}{|c|}{ Referrals $\star$} & \multicolumn{2}{|c|}{ Consultations $\nmid$} & \multicolumn{2}{|c|}{ Referrals ${ }^{\star}$} & \multicolumn{2}{|c|}{ Consultations $\dagger$} \\
\hline & No & $\%$ & No & $\%$ & No & $\%$ & No & $\%$ \\
\hline A & 24 & $47(34$ to 61$)$ & 98 & $26(22$ to 30$)$ & 3 & $12(-1$ to 24$)$ & 24 & $15(10$ to 21$)$ \\
\hline B & 3 & $6(1$ to 12$)$ & 83 & 22 (18 to 26$)$ & & & 7 & $5(1$ to 8$)$ \\
\hline $\mathrm{C}$ & 9 & $18(5$ to 31$)$ & 107 & 28 (24 to 33$)$ & 21 & 81 (66 to 96$)$ & 89 & $57(49$ to 65$)$ \\
\hline D & 15 & 29 (17 to 42$)$ & 46 & $12(9$ to 15$)$ & 2 & $8(-3$ to 18$)$ & 19 & $12(7$ to 17$)$ \\
\hline $\mathrm{E}$ & & & 45 & 12 (9 to 15 ) & & & 17 & 11 ( 6 to 16$)$ \\
\hline Total & 51 & & 379 & & 26 & & 156 & \\
\hline
\end{tabular}

for the lowest referring doctor to 3.9 for the highest referring doctor.) Among these 612 outpatient referrals, initial reply letters from the hospital were received for $395(65 \%$ of the total referrals made over study period), and these referrals were included in further analysis. Of these 395 referrals, $351(89 \%)$ were to the NHS and $44(11 \%)$ were private referrals.

Analysis of the data showed substantial differences in the proportions of referrals to individual specialties by the five doctors. Application of the method to distinguish between random and systematic variation in referral rates showed significant systematic variation (at the $1 \%$ level) in referral rates between the five doctors for four specialties - otorhinolaryngology, ophthalmology, general surgery, and dermatology (table I). Two of these four specialties were subjects in which the high referring doctors had particular expertise - namely, otorhinolaryngology and ophthalmology. This was an unexpected finding, and further data were collected to estimate differences in case mix of patients seen by the five doctors.

Table II shows referrals and consultations for otorhinolaryngology and ophthalmology problems. As the data were collected over different periods, precise calculations of referral rates specific to specialties are not possible, but several conclusions are clear from these data. Doctor A (hospital practitioner in otorhinolaryngology) made $47 \%$ of the otorhinolaryngology referrals ( $95 \%$ confidence interval $34 \%$ to $61 \%$ ) while undertaking only $26 \%$ ( $22 \%$ to $30 \%$ ) of otorhinolaryngology consultations. Doctor $\mathrm{C}$ (experienced in ophthalmology) made $81 \%(66 \%$ to $96 \%)$ of the ophthalmology referrals. This seems to be partly, but not completely, accounted for by differences in case mix because he saw $57 \%(49 \%$ to $65 \%)$ of all eye problems.

Analysis of the questionnaire subsequently used to assess confidence within specialties showed that all three high referrers (doctor A for otorhinolaryngology, doctor $\mathrm{C}$ for ophthalmology, and doctor $\mathrm{D}$ for dermatology and general surgery) felt "more confident than average" in managing problems relating to the special- ties in which they were high referrers, so it was not possible to explain the high referral rates in terms of perceived lack of confidence in those clinical areas.

\section{Discussion}

The performance of general practitioners in making outpatient referrals to hospital has attracted much attention in recent years. Of particular interest is the apparent wide variation in referral rates among general practitioners, with studies suggesting at least fourfold variation between the highest and lowest referral rates. One possible interpretation of this variation is that high rates may indicate overreferral, with a significant proportion of unnecessary, inappropriate referrals wasting hospital resources, while low rates might suggest underreferral, resulting in increased morbidity among patients who would otherwise benefit from referral. Much interest has been focused on the possible role of audit of referral patterns as a means of identifying inappropriate referral and so optimising general practitioners' use of hospital resources.

In this study the overall referral rate per 100 consultations was $2 \cdot 8$, a fairly low rate compared with other studies, which showed rates of $3 \cdot 2$ to $6 \cdot 1$ referrals per 100 consultations. ${ }^{5}$ Further analysis of the individual patterns of referral of the practitioners in this study, however, confirms that the level of a crude referral rate cannot be taken as an accurate measure of referral performance within specialties.

The overall distribution of referrals among the various specialties in this study matches that found in a previous study. ${ }^{6}$ Of particular interest is the high number of referrals in two specialties (otorhinolaryngology and ophthalmology) by practitioners with expertise in them. A high referral rate by a doctor with expertise within a specialty may be the result of a differential case mix, with that doctor seeing more cases within that specialty either because of intrapractice referral from partners or initial selection by patients aware of this expertise. Our analysis of the case mix of consultations of the practitioners in this study suggests that differences in case mix cannot fully explain the high referral rates of these two doctors in otorhinolaryngology and ophthalmology. It should be noted, however, that a high referral rate for specific specialties may not be incompatible with "expert" doctors having the same referral rate as their partners for a given problem in that specialty, because doctors with expertise may see not just more cases but more difficult cases sent to them by their partners. Indeed, we were aware that some referral of problems to other partners takes place in this practice. Such an effect could be allowed for with a qualitative (rather than quantitative) assessment of case mix, measuring degrees of severity of problems by individual case 
analysis, rather than simply counting consultations in each specialty.

Measurement of referral rates in this study was complicated by the fact that we were able to include only patients referred and seen during the study period, and it is possible - though we have no evidence for it -that doctors with close links to particular hospital departments arranged for their patients to be seen more rapidly, introducing bias into our calculation of referral rates. Nevertheless, it still seems likely, given the magnitude of the observed differences, that the doctors with particular expertise in otorhinolaryngology and ophthalmology had high referral rates to those specialties. It does not, of course, follow that their referrals were appropriate. It may be that "expert" general practitioners sometimes overrefer. This might be the case if, for example, doctors with extensive hospital experience put greater reliance on hospital based investigations than would normally be expected of a primary care physician. This does not, however, negate our overall conclusion from this study that a high rate of referral cannot necessarily be taken to indicate inappropriate referral. This conclusion is supported by a recent study showing that doctors with high referral rates have high elective admission rates? and by a detailed qualitative study that found no difference in the appropriateness of referrals between general practitioners with high and average rates of referral. ${ }^{8}$ Meaningful assessment of referral performance requires assessment of the appropriateness of individual referral decisions.

In the light of current moves requiring general practices to produce an annual report including referral rates, family health services authorities should exercise great caution when interpreting crude referral rates. It may be that good doctors refer more patients to hospital.

We thank the doctors and staff of the Poplars Surgery, Castle Bromwich, for cooperation with this study.

1 Evans EO, McBride K. Hospital usage by a group practice. $f \mathrm{R}$ Coll Gen Pract 1968;16:294-306.

2 Morrell DC, Gage HG, Robinson A. Referral to hospital by general practitioners. I R Coll Gen Pract 1971;21:77-85.

$3 \mathrm{McPherson} \mathrm{K}$, Wennberg J, Hovind OB, Clifford P. Small area variations in the use of common surgical procedures: an international comparison of New use of common surgical procedures: an international compar
England, England and Norway. $N$ Engl $F$ Med 1982;307:1310-4.

4 Roland MO, Bartholomew J, Morrell DC, McDermott A, Paul E. Understanding hospital referral rates: a user's guide. BMJ 1990;301:98-102.

5 Wilkin D, Smith A. Explaining variation in general practitioner referrals to Wilkin D, Smith A. Explaining va
hospital. Fam Pract 1987;4:160-9.

6 Coulter A, Noone A, Goldacre M. General practitioners' referrals to specialist outpatient clinics. BMF 1989;299:304-8.

7 Coulter A, Seagroatt V, McPherson K. Relationship between general practices' outpatient referral rates and rates of elective admission to hospital. BMf 1990;301:273-6.

8 Knottnerus JA, Joosten J, Daams J. Comparing the quality of referrals of general practitioners with high and average referral rates: an independent panel review. Br f Gen Pract 1990;40:178-81.

(Accepted 17 April 1991)

\section{MATERIA NON MEDICA}

\section{The night I slept with a patient}

I suppose that all this would be frowned on now, in the year 1991,40 or so years since it happened to me. But in the circumstances it seemed a natural thing to do.

She was a charming woman, happily married, but had had no children. They lived in a typical Edwardian terrace house, "two up and two down," with a tiny scullery overlooking a strip of garden at the back of the house. The kitchen held a black leaded solid iron range with brass knobs and a home made, multicoloured, tufted rag rug at its front. At each side stood a Windsor high back chair. A cosy place.

A steep, almost vertical, staircase led to the two bedrooms: lace curtains at the windows, patchwork quilt on the bed over snow white sheets. A small iron grate held a coal fire, throwing light into the gloom. A gaslight above the fire was covered by a translucent pink glass globe. The flickering of the gas jet reminded me of my own bedroom as a child in Yorkshire.

She had been waiting for me patiently. She was about to produce twins and had an elderly, wise midwife in readiness.

In the 1940s a village general practitioner was used to home confinements and his "midder" bag was always ready-white gown, rubber gloves, and most of the instruments that such part time accoucheurs relied on, forceps, sutures, the lot. And the ubiquitous chloroform with dropper bottle.

She was lying calmly on the bed, which occupied most of the room. I was very tired. It had been a long day, many home visits. Sometimes we had more than 100 between morning and evening surgeries, sandwiches eaten in the car.
The first infant arrived with no great difficulty, which at the time seemed unusual, it having had to do the harder job of leading the way. It was wrapped in its blanket and put in the cot. Then came the time for patience and Nature to complete the job. We were sternly taught to wait for the second twin in the same way that we waited for a placenta to separate. No forced attempts to hurry a natural process. My old professor at University College Hospital was adamant in this and I rarely found him to be mistaken.

There seems to be no fixed time for the following twin to decide to enter this world. I sat on the edge of the bed hoping for early signs of arrival. The patient, pleased by the way things were going, in no way discomfited by any great strain, turned on her back, saw my yawn and said: "You must be tired, Doc." Manfully, I denied it: "All part of the day's work." She, that remarkable woman, patted the sheet, said: "Why don't you lie down for a bit? I'll keep guard." Such an offer could not be refused, and I subsided next to her, facing the edge of the bed. That was one of the sweetest sleeps I have ever enjoyed. How long it lasted I do not know, but I was wakened by her hand, patting again: "It's coming, Doc."

The second child, also a boy, took even less time to be delivered, and his cries woke husband and midwife from their chairs at the fireside. Another "home baby" case done, with that unique warm glow of simple satisfaction, perhaps the major pleasure of general practice, of mutual respect and trust.

There was a sad end to this story. She had called the first twin Richard that same night, but my small namesake died the following day - a tentorial tear at postmortem.

A rebuke from the gods?-RICHARD MAWSON, retired general practitioner, Hertfordshire 